\title{
Rehabilitation strategies and results in patients treated with chemoradiotherapy/radiotherapy for head and neck cancer: Institutional experience
}

\begin{abstract}
Oncologic treatments, such as Radio- therapy and Chemo-radiation, for head and neck cancer can cause long-term swallowing impairments (dysphagia) that negatively impact the Quality of life. Radiation-induced dysphagia consists of a broad spectrum of structural, mechanical, and neurologic deficits. The goal of this study is to understand the importance of Onco Rehabilitation during Radiation and Chemo-Radiation to minimize the incidence of Dysphagia during the Treatment, which ultimately causes delay in Overall Treatment Time (OTT).
\end{abstract}

Volume I3 Issue 3 - 202I

\author{
Ankita Patel, Gaurav Goswami, Neha Gupta, \\ Soumyahree Samanataray, Deepak Kumar \\ Singh, Rafi, Anurag Dixit, SK.Singh, Anand \\ Kumar, Swaroop Patel,Akhil Sareen \\ Apex Super Specialty Hospital,Varanasi, India
}

Correspondence: Dr Dibyendu Roy, Onco Rehabilitation, Apex Hospital,Varanasi, India, Tel 9748344997. Email droy.corel@gmail.com

Received: April 0I, 202I | Published: August 20, 202 |
Oral cancer is the most common cancer in India amongst men (16.1 $\%$ of all cancers). Oral cancer is the second most common cancer in India amongst women ( $10.4 \%$ of all cancers). ${ }^{1}$ Around $80-90 \%$ of oral cancers are directly attributable to tobacco use. ${ }^{2}$ The mean age of oral cancer is 50 years. ${ }^{3}$ Survival rate is (5-years). ${ }^{4}$ The three main types of treatment for managing head and neck cancer are Radiation therapy, Surgery, and Chemotherapy. The primary treatments are radiation therapy, surgery, or both combined; chemotherapy is often used as an additional, or adjuvant, treatment. The optimal combination of the three treatment modalities for a patient with a particular head and neck cancer depends on the site of the cancer and the stage (extent) of the disease. ${ }^{5}$

Radiation therapy disrupts tissue homeostasis by damaging deoxyribonucleic acid (DNA) in the nucleus of rapidly proliferating cells and disrupts the normal function of the surrounding cells. ${ }^{6}$ Radiation injuries are clinically classified into Acute, Sub-acute or Chronic. Early mucosal injuries are attributed to cell death and subsequent inflammation. ${ }^{7}$ which Causes Oral Mucositis and Xerostomia. Late deeper tissue responses are attributed to damage to the vasculature and/or surrounding connective tissue.

One of the most detrimental effects of radiation exposure is the induction of excessive production of Reactive oxygen and nitrogen species (ROS). Reactive species are generated during normal and disease conditions through an oxidative metabolic process within organelles or through an enzymatic source. When an imbalance occurs between reactive species and their antioxidant defenses, it can lead to cell stress and eventual tissue destruction, called oxidative damage. ${ }^{8}$ Skeletal Muscle Injury is also a detrimental effect of Radiation Therapy. The degree of skeletal muscle injury during radiation is dependent on location and variety of tissue types affected.9-12 Previously it was thought that skeletal muscles are Radiation resistant because of latent mitotic activity of skeletal muscles. ${ }^{13}$ But functional decline, muscle weakness and poor range of movement is commonly reported in Head and neck cancer survivors. ${ }^{14-16}$ Head and neck cancer survivors often present with Pharyngeal immobility including impaired bolus movement including impaired bolus movement during swallow and post-swallow residue in the posterior pharyngeal wall, laryngeal vestibule, and Pyriform sinus. ${ }^{17}$

Perturbations in motor and sensory pathways can occur as result of early or late radiation injuries, influencing airway. ${ }^{18}$ Peripheral nerves which are innervating swallowing musculature can be affected by Radiation Therapy. Radiation Therapy can cause thermal and mechanical damage which ultimately trigger a cascade of inflammatory mediators like cytokines, neuropeptides and glutamate signals in oral mucosa. ${ }^{19}$ Oral Mucositis is the most common complication of radiation therapy, which breaks down the epithelium lining causing significant pain and discomfort. Nociceptive pain receptors get depolarised in response to oxidative stress. ${ }^{20}$ Persistent or uncontrolled pain can result from neuropathic sensory dysfunction. ${ }^{21}$ Acute inflammation trauma to vocal folds can elicit immune reactive effects to sensory in the brain stem .Inflammation and fibrosis can alter the muscle and nerve electrophysiology. Sensory inputs like bolus size, taste can be altered due to radiation therapy. Initiation and regulation of cough and swallowing reflex can be altered due to radiation therapy. ${ }^{22}$ Permanent injury to the lower cranial nerves is a ra progressive complication of radiation therapy. Bulbar palsy is the most common symptom of radiation induced neuropathies in head and neck squamous cell carcinoma. . This happens because the proximity of cranial nerves to the radiation field and near to the highly susceptible fibrosis area. ${ }^{23}$

In our Institute we have added Prophylactic Oro-Motor and Swallowing Exercises and Photobiomodulation therapy from the very beginning of Chemo-Radiation therapy to improve the long term swallowing outcomes and reduce the pain sensitivity due to oral mucositis.

\section{Discussion}

Prophylactic Oro motor exercises and swallowing exercises and Pharyngocise can be used to increase muscle fatigue resistance attributed to alteration in mitochondria biogenesis, myofiber strength 
and inhibition of oxidative stress. ${ }^{24-26}$ Active skeletal muscles are predisposed to high level of oxidative production, due to rapid increase in ROS , which produced during muscle contraction. ${ }^{27}$ It is crucial that myofibres in swallowing muscles have efficient antioxidant capabilities to combat Radiation induced ROS. All the patients who have undergone the Prophylactic Swallowing exercises during Chemo-Radiation had more normal tongue base and more normal epiglottic inversion. . Patients have less structural changes in Genioglossus, Hypoglossus and myolohyoid muscles . Yawning (Pharyngocise) helps the upward movement of the larynx and the opening of the oesophagus . Effortful swallow (Pharyngocise) improves the movement of the tongue base and pharynx. Medelsohns manœuvre (Pharyngocise) promotes movement of the epiglottis which improves the function of the larynx and strength of the oesophageal opening. Maskao Manouever (Pharyngocise) helps to strengthen tongue muscles for swallowing. Epiglotic control (Pharyngocise) improves the airway protection during swallowing. Shakers manœuvre(Pharyngocise) improves th movement of epiglottis and strengthen the opening of oesophagus . It promotes the upward movement of the larynx. Resistive tongue exercises (Pharyngocise) improves the tongue strength and control of food and drink. ${ }^{28}$

The Photobiomodulation mechanism has been described as an activation of energy production by the cytochromes in the mitochondria of oral mucosa cells, by the transmission of electrons. ${ }^{29}$ The Photobiomodulation promotes rapid regeneration of the myofibroblasts originating in the fibroblasts and the growth factors of these fibroblasts maintain repair and cytotoxic protection. ${ }^{30}$

\section{Acknowledgments}

None.

\section{Funding}

None.

\section{Conflicts of interest}

The Authors do not refer to Conflict of interest.

\section{References}

1. http://cancerindia.org.in/cancer-statistics/

2. NCRP - Consolidated Report of Hospital Based Cancer Registries 20072011, National Cancer Registry Programme (Indian Council of Medical Research). 2013

3. Shenoi R, Devrukhkar VC, Sharma BK, et al. Demographic and clinical profile of oral squamous cell carcinoma patients: a retrospective study. Indian J Cancer. 2012;49(1):21-26.

4. Iype EM, Pandey M, Mathew A, et al. Oral cancer among patients under the age of 35 years. J Postgrad Med. 2001;47(3):171-176.

5. https://www.radiologyinfo.org/en/info.cfm?pg=hdneck\#: :text=The three main types of treatment for managing, often used as an additional $\% 2 \mathrm{C}$ or adjuvant $\% 2 \mathrm{C}$ treatment.

6. Barcellos-Hoff MH, Park C, Wright EG. Radiation and the microenvironment-tumorigenesis and therapy. Nat Rev Cancer. 2005;5(11):867-875.

7. Bentzen SM. Preventing or reducing late side effects of radiation therapy: radiobiology meets molecular pathology. Nat Rev Cancer. 2006;6(9):702713.

8. Kam WW, Banati RB. Effects of ionizing radiation on mito- chondria Free Radic Biol Med. 2013;65:607-619.
9. Levendag PC, Teguh DN, Voet P, et al. Dysphagia disorders in patients with cancer of the oropharynx are significantly affected by the radiation therapy dose to the superior and middle constrictor muscle: a dose-effect relationship. Radiother Oncol. 2007;85(1):64-73.

10. Caudell JJ, Schaner PE, Desmond RA, et al.. Dosimetric factors associated with long-term dysphagia after definitive radiotherapy for squamous cell car-cinoma of the head and neck. Int J Radiat Oncol Biol Phys. 2010;76(2):403-409.

11. Caglar HB, Tishler RB, Othus M, et al. Dose to larynx predicts for swallowing com-plications after intensity-modulated radiotherapy. Int $J$ Radiat Oncol Biol Phys. 2008;72(4):1110-1118.

12. Starmer HM, Quon H, Kumar R, Alcorn S, Murano E, Jones B, Humbert I. The Effect of Radiation Dose on Swallowing: Evaluation of Aspiration and Kinematics. Dysphagia. 2015;30(4):430-437.

13. Gillette EL, Mahler PA, Powers BE, et al. Late radiation injury to muscle and peripheral nerves. Int JRadiat Oncol Biol Phys. 1995;31(5):130913018.

14. Silver HJ, Dietrich MS, Murphy BA. Changes in body mass, energy balance, physical function, and inflammatory state in patients with locally advanced head and neck cancer treated with concurrent chemoradiation after low-dose induction chemotherapy. Head Neck. 2007;29(10):893900.

15. Hutcheson KA, Lewin JS, Barringer DA, et al. Late dysphagia after radiotherapy- based treatment of head and neck cancer. Cancer. 2012;118(23):5793-5799.

16. Bleier BS, Levine MS, Mick R, et al. Dysphagia after chemoradiation: anal- ysis by modified barium swallow. Ann Otol Rhinol Laryngol. 2007;116(11):837-841.

17. Lazarus CL, Logemann JA, Pauloski BR, et al. Swallowing disorders in head and neck cancer patients treated with radiotherapy and adjuvant chemotherapy. Laryngoscope. 1996;106(9 Pt 1):1157-1166.

18. Hutcheson KA, Lewin JS, Barringer DA, et al. Late dysphagia after radiotherapy- based treatment of head and neck cancer. Cancer. 2012;118(23):5793-5799.

19. Holzer P. Transient receptor potential (TRP) channels as drug targets for diseases of the digestive system. Pharmacol Ther. 011;131(1):142-170.

20. Viet CT, Corby PM, Akinwande A, et al. Review of preclinical studies on treatment of mucositis and associated pain. J Dent Res. 2014;93(9):868 875.

21. Simonyan K, Feng X, Henriquez VM, et al. Combined laryngeal inflammation and trauma mediate long-lasting immunoreactivity response in the brainstem sensory nuclei in the rat. Front Integr Neurosci. 2012;6:97.

22. Steele CM, Miller AJ. Sensory input pathways and mechanisms in swallowing: a review. Dysphagia. 2010;25(4):323-333.

23. Lin YS, Jen YM, Lin JC. Radiation-related cranial nerve palsy in patients with nasopharyngeal carcinoma. Cancer. 2002;95(2): 404-409.

24. Hood DA. Invited Review: contractile activity-induced mito- chondrial biogenesis in skeletal muscle. J Appl Physiol. 2001;90(3):1137-1157.

25. Adhihetty PJ, Irrcher I, Joseph AM, et al. Plasticity of skeletal muscle mitochondria in response to con- tractile activity. Exp Physiol. 2003;88(1):99-107.

26. Scheele C, Nielsen S, Pedersen BK. ROS and myokines promote muscle adaptation to exercise. Trends Endocrinol Metabolism: TEM. 2009;20(3):95-99.

27. Venditti P, Masullo P, Di Meo S. Effect of training on $\mathrm{H}(2) \mathrm{O}(2)$ release by mitochondria from rat skeletal muscle. Arch Biochem Biophys. 1999;372(2):315-320. 
28. https://www.uhn.ca/PatientsFamilies/Health_Information/Health_Topics/ Documents/Swallowing_Exercises_for_Patients_with_Head_and_Neck_ Cancer_Receiving_Radiation_Treatment.pdf

29. Karu T. Photobiology of lower laser effects. Health Phys. 1989;56(5):691704.
30. Pourreau-Schneider N, Ahmed A, Soudry M, et al. Helium-neon laser treatment transforms fibroblasts into myofibroblasts. Am J Pathol. 1990;137(1):171-178. 